\section{( EDITOR'S \\ CHOICE}

\section{Correspondence to} Jessica Flanigan, Jepson School of Leadership Studies, University of Richmond, Richmond, Virginia, USA; jessica.flanigan@gmail.com

Received 15 September 2011 Revised 8 March 2012 Accepted 16 March 2012

Published Online First 26 July 2012

\title{
Three arguments against prescription requirements
}

\author{
Jessica Flanigan
}

\section{ABSTRACT}

In this essay, I argue that prescription drug laws violate patients' rights to self-medication. Patients have rights to self-medication for the same reasons they have rights to refuse medical treatment according to the doctrine of informed consent (DIC). Since we should accept the DIC, we ought to reject paternalistic prohibitions of prescription drugs and respect the right of selfmedication. In section 1, I frame the puzzle of self-medication; why don't the same considerations that tell in favour of informed consent also justify a right of self-medication? In section 2, I show that the prescription drug system was historically motivated by paternalism. In section 3, I outline the justifications for the DIC in more detail. I show that consequentialist, epistemic, and deontic considerations justify the DIC. In sections 4-6, I argue that these considerations also justify rights of self-medication. I then propose that rights of self-medication require non-prohibitive prescription policies in section 7. I consider two objections in sections 8 and 9: that patients ought not to make medically risky or deadly decisions, and that unrestricted access to prescription-grade pharmaceuticals would result in widespread misuse and abuse. Section 10 concludes.

\section{THE PUZZLE}

Consider the following two cases:

Risky refusal: Debbie has diabetes and her physician advises her to start insulin treatment. Debbie understands the risks of refusing insulin, but is also unwilling to live by a schedule and monitor her medication. Against medical advice, Debbie decides to try to manage her diabetes with diet and exercise. Debbie's physician is morally and legally prohibited from injecting Debbie with insulin against her wishes.

Risky access: Danny has diabetes and his physician advises him treat his condition with diet and exercise. Danny doesn't want to invest the time or energy in diet and exercise, and would prefer to just begin using insulin right away. Against medical advice, Danny wishes to try to manage his diabetes with insulin. However, Danny cannot legally access diabetes medication without a prescription from his physician.

In risky refusal, Debbie has the right to refuse insulin treatment against medical advice. Indeed, it would be immoral for Debbie's physician to force her to use insulin, to mislead her about the risks and benefits of treatment, to lie to Debbie about her condition or to coerce her into taking the treatment. All physicians are obligated to respect the doctrine of informed consent, which states that patients are entitled to refuse any medical treatment, even against advice. Yet in risky access Danny's authority to make treatment decisions is not similarly protected. Danny is legally prohibited from carrying out his treatment plans.

This discussion raises the following puzzle. If patients are entitled to make refusal decisions without coercive or deceptive interference, then why are they not similarly entitled to make treatment decisions more generally, including the decision to use prescription drugs?

At first, it may seem unclear why this is a puzzle. The bare fact that competent patients have the right to refuse medical treatment does not entail or imply that patients have the right to access that medical treatment as well. After all, people have rights to refuse all sorts of goods and services that they do not have the right to access. You might have a right to refuse to participate in an exclusive club or fraternity that you don't have a right to access independently. People have rights not to be killed, but a right to die doesn't follow. Similarly, the bare right to refuse medical treatment is like the right against battery, and a right against battery does not establish a right to risk dangerous interventions.

Yet the puzzle arises when the right of refusal is understood within the context of the doctrine of informed consent (DIC) and medical practice as a whole. The prescription drug system entails a degree of paternalism that is sharply at odds with the rest of medical practice. This anomaly cries out for justification or explanation. As Miller and Wertheimer write:

\begin{abstract}
"If we look at the literature on the ethics of medical care, we will encounter vigorous and (almost) unanimous arguments against paternalism. The dominant philosophical view has privileged respect for autonomy as a guiding principle over the ancient Hippocratic tradition that the physician is entitled to decide what treatment is best for his patients. There is a near universal consensus that patients have the right to refuse treatment even if the physician (rightly) thinks that the patient is mistaken, and that physicians should not deceive or withhold information from patients, even when they think it is in the patient's interests to do so. Anti-paternalism appears to reign. ${ }^{1 "}$
\end{abstract}

Even if administering a treatment without consent, coercing a patient, withholding a diagnosis, misleading a patient, or lying about the nature of a procedure would make a patient better off, these practices are impermissible. Presumably, limitations on patients' access to prescription drugs are also intended to promote patients' best interests. Yet, if paternalist medical interventions are impermissible, why aren't paternalist limitations on self-medication also impermissible?

\section{THE PRESCRIPTION DRUG SYSTEM}

All developed countries face this puzzle because all developed countries have prescription drug 
systems. The history of the prescription drug system in the USA highlights its paternalistic motivation. In the 19th century, patients and politicians agreed that citizens had rights of selfmedication and that restrictions on access to therapeutic medicines were considered as unjust as restrictions on speech or conscience. ${ }^{2}$ At this time, drugs were not regulated differently from any other consumer goods. In 1902, contaminated smallpox vaccines caused several deaths, so the US Congress created the agency that would become the FDA to oversee premarket testing for all drugs, and to set and enforce labelling requirements. This power expanded in 1938 when a dangerous antibacterial drug, elixir sulfanilamide, caused 107 deaths. The public responded forcefully to the elixir sulfanilamide disaster, and called for still more government oversight of new drugs. In response, Congress granted the FDA the power to prohibit drugs that were not approved for safety and to require mandatory prescriptions for many new drugs. Though the Act states that it is 'intended to make self-medication safer and more effective,' it effectively limited patients' ability to self-medicate by designating regulators and physicians as gatekeepers to medical treatment. Over the course of the 20th century, pharmaceutical regulation expanded and today all developed countries have adopted similar systems for regulating access to prescription drugs.

In addition to prescription-only status, most other countries also designate some drugs as 'behind the counter' meaning that a physician's notice isn't necessary if a patient consults a pharmacist before purchasing a drug. Still, for large categories of drugs-for example, psychotherapeutic and analgesic medicines, a prescription is required.

Importantly, prescription requirements are justified for paternalistic reasons: physicians are empowered by governments to limit patients' access to medicines out of a concern that patients with unrestricted access would otherwise make inadvisable treatment decisions, or misuse or abuse potentially dangerous medicines.

I will argue that prohibitive prescription requirements violate patient's rights to self-medication. Instead, I favour a nonprohibitive drug system and I will argue that prescription-grade drugs should be widely available without a physician's notice.

\section{THE DOCTRINE OF INFORMED CONSENT}

Interestingly, paternalistic prescription drug systems historically developed just as medical professionals adopted anti-paternalistic principles-namely, the DIC. Just as patients became empowered to refuse treatments, their access to treatment decreased.

For example, in the USA the DIC became law through a series of court cases, which then led to reforms in clinical practice. ${ }^{3}$ Initially, the justification for the expansion of patients' rights was derived from the idea that people had rights against assault and battery or, more generally, rights to bodily integrity. As legal and ethical standards of treatment expanded from consent to informed consent, the justification for expansion of patient authority changed as well. The legal doctrine of informed consent emerged in 1957 with Salgo v. Leland Stanford Jr. University Board of Trustees. ${ }^{4}$ In this case, Martin Salgo was rendered permanently paralysed by an operation that he consented to, though he claimed that his consent was compromised since he had not been informed of the risks associated with the procedure. The courts agreed, and affirmed that physicians had not only a duty to secure consent for medical treatment, but also to provide patients with any information about a medical decision necessary for consent.
In order to obtain informed consent physicians must now disclose information about treatment options, diagnosis, and prognosis. Before DIC, patients only had the authority to refuse treatment. This meant that physicians would routinely withhold information about diagnoses 'for the patients own good' and would also misrepresent the risks and benefits of treatment decisions. ${ }^{4}$ New disclosure requirements developed with DIC to enable patients to play a more active and informed role in choosing or declining a particular treatment over alternatives.

A patient must meet three criteria in order to give informed consent. ${ }^{5}$ First, she must be mentally competent. For this reason, unconscious, severely mentally disabled, intoxicated, and underage patients are often not considered capable of giving informed consent. Second, she must be informed, meaning that any information that a reasonable layperson would find relevant to a treatment decision has been disclosed and explained. Third, she must give her consent freely. If a competent, informed patient only consents because of pressure or coercion, the physician still has not secured informed consent.

I will focus on three reasons that have been widely cited in favour of the DIC:

Medical outcomes: In general, DIC leads to better medical outcomes.

Epistemic authority: Physicians ought to treat the whole patient, not just the condition. Patients can assess what is in their overall interest better than physicians, so physicians should defer to patients' judgements about treatment decisions.

Normative authority: Patients have the sole authority to make self-regarding treatment decisions even if it is not in their overall interest to do so.

The first two justifications are broadly consequentialist. 'Medical outcomes' is based on the empirical premise that institutional protections for DIC will promote patients' medical interests on balance, even though it enables patients to make medically inadvisable treatment decisions in particular cases. $\mathrm{R}$ Gillon puts the argument like this:

"Far more harm than good would result from a social or moral
system that permits, let alone requires, compulsory medical
treatment-even life saving treatment-of competent adults in
cases where those adults have competently and voluntarily rejected
that treatment."

This is an empirical conjecture, which I will not assess here except to note that there are several ways that a disregard for DIC might lead to worse medical outcomes. Good medical care requires relationships of trust between physicians and patients. Patients who know that their physicians won't coerce, trick, or mislead them are more likely to seek medical care, honestly disclose relevant information to their physicians and report that they are satisfied with medical outcomes.

The epistemic justification for the doctrine of informed consent is grounded in the idea that medicine ought to aim to treat the whole patient, not just her condition, and while physicians are experts about health, patients are experts about their overall well-being. Therefore, physicians ought to defer to patients' judgement about treatment options. ${ }^{5}$ This idea originates with Mill, who famously argued in On Liberty:

"Neither one person, nor any number of persons, is warranted in saying to another human creature of ripe years, that he shall not do with his life for his own benefit what he chooses to do with it. He is the person most interested in his own well-being, the interest which any other person, except in cases of strong personal attachment, can have in it, is trifling, compared with that which he himself has." 
Bioethicists have affirmed this sentiment. Robert Veatch writes,

"There is no reason to believe that a physician or any other expert in only one component of well-being should be able to determine what constitutes the good for another being. ${ }^{9 "}$

The following examples illustrate the epistemic justification for DIC. Imagine a patient who is deeply religious and believes that it is wrong to accept medically advisable blood transfusions. Given her cultural identity and religious commitments, her overall interests are better served by making a medically inadvisable decision. Or, we might imagine a patient with cancer who refuses chemotherapy in an effort to preserve her fertility, even though chemotherapy is in her medical interest. In cases like these the DIC holds that patient's judgement about her overall interests ought to prevail because health is only one among many values that are relevant to a patient's medical decision-making.

Third, the strongest most widely cited justification for the DIC is the 'normative authority' justification, which states that patient autonomy is morally valuable even if respecting a patient's decisions isn't in her medical or overall interest. ${ }^{10}$ For example, according to DIC, even if hearing news of a terminal diagnosis would make a patient's remaining days medically worse off and objectively worse overall, and indeed if a patient would prefer that she never found out about the diagnosis, physicians still must disclose diagnostic information to their patients.

This justification for DIC relies on the premise that "patient autonomy' is a value and, importantly, that physicians ought foremost to respect patient autonomy, not promote it. That is, according to DIC physicians are charged first with respecting the autonomous choices their patients make, and only furthering a patient's autonomous capacities in ways that accord with due respect. Even if a patient's treatment decision makes her less autonomous in the long term, physicians still are prohibited from interfering with that decision. ${ }^{10}$ For example, if a patient decides to refuse lifesaving treatment her decision will fully destroy her autonomous capacities, and physicians cannot permissibly over-ride such a decision or mislead or coerce her to accept lifesaving treatment according to DIC. Examples like these abound: patients have the right to refuse operations that will save their limbs, refuse treatment that will extend their lives, and refuse treatment that will preserve their cognitive capacities. In all these cases, DIC protects a patient's right to refuse treatment even when refusal will undermine her autonomous capacities in the long run.

There are several reasons to accept this justification for DIC. First, the idea that autonomous people have the "normative authority' to make self-regarding decisions without coercive or deceptive interference rests on a solid base of support in normative ethics, particularly the neo-Kantian and contractualist that have been well developed by Christine Korsgaard, Stephen Darwall and TM Scanlon, respectively. ${ }^{11-13}$ Whatever the normative ethical underpinning, the core of the moral justification for informed consent appeals to the widespread beliefs that each person is entitled to "power over the proceedings' for decisions that effect her, and that the right to make intimate and personal decisions about one's own body is fundamental. As Tom Beauchamp has argued, the value of autonomy is affirmed by a plurality of moral theories and is one of our moral convictions that inspires widespread confidence with little apparent bias. ${ }^{14}$ This sentiment is also reflected in legislation and court decisions that affirm other basic rights to make self-regarding intimate and personal decisions, particularly those that are especially important to people. Like other basic rights, self-regarding decisions about our own bodies warrant particularly strong protections from state interference, even if such interference is designed to promote citizens' own welfare or overall autonomous capacities.

This interpretation of patient autonomy, as a value that physicians should respect, comports with more widely held intuitions about the value of autonomy. While some hard-nosed neo-Kantians disagree, most affirm that our autonomous capacities are not so valuable in themselves that the moral importance of an autonomous will trump the value of respecting autonomous choices. ${ }^{15}$ To say otherwise seems to deny that people can permissibly choose to get drunk, ride roller coasters, stand on their heads for a long time, binge eat, fail to exercise, or watch reality television, because all these activities also can undermine or alter one's autonomous capacities either temporarily or permanently. The normative authority justification is not a kind of autonomy-promoting consequentialism. Rather, it is a thoroughly non-consequentialist constraint on the conduct of physicians.

This interpretation of the value of patient autonomy is the best explanation for DIC in theory and practice. An essential commitment of DIC is that a physician acts wrongly if he misleads or coerces a patient into having an operation (say, taking out a few non-vital body parts). DIC prohibits such actions even if an operation on patient $A$ would benefit patients $B$ and $C$ (by redistributing A's organs to them), and even if on balance the violation of patient A's normative authority to refuse treatment made the set of patients ( $A, B$ and $C$ ) more autonomous overall. For the same reason physicians act wrongly and violate DIC if they coerce or mislead a patient at time $t_{a}$ in order to ensure that the patient is maximally autonomous over the extended time of $t_{a}, t_{b}$ and $t_{c}$. DIC therefore is committed to the idea that patient autonomy is not a value that physicians should maximise or promote between patients or over the course of a patient's life; it's a value that physicians should respect.

One asymmetry between the synchronic and diachronic cases above is that patients cannot permissibly decide to undermine other's autonomous capacities, but patients can make decisions that limit the autonomous capacities of their future selves. For example, if a patient pre-discloses that she doesn't want to know her diagnostic or treatment information, this kind of practice is not incompatible with the 'normative authority' justification for informed consent. Just as patients are entitled to autonomously make risky or dangerous decisions that have longterm consequences for their well-being, so too are patients entitled to autonomously make decisions that have consequences for their level of autonomy. For example, GT Laurie has argued that patients have rights not to know genetic information if they give advanced consent that the information be withheld. ${ }^{16}$ On the other hand, advanced directives only go so far, and a patient's prior wishes not to know are not authoritative if the patient competently changes her mind. ${ }^{17}$

For these reasons, even if a patient's refusal decision would make her medically worse off, worse off all things considered, and even if a refusal decision would undermine her autonomous capacities, patients are nevertheless entitled to refuse medical treatment. Further, any coercive or deceptive interference in the patient's refusal-decision is wrong.

Before I continue, a note about methodology is in order. My argument is intended to build on principles that are affirmed by existing justifications for DIC. While I maintain that the 
normative authority justification is the strongest, my goal in this essay is to show that all three credible justifications for DIC tell in favour of self-medication. I will therefore show that a right of self-medication does not rely on any particular (and for some, controversial) normative premise but rather that a right of self-medication is as broadly supported as DIC. Both consequentialists and non-consequentialists have reason to support self-medication. For this reason, patients have rights of selfmedication even if self-medication would lead to worse medical and overall outcomes. Yet a right of self-medication would promote patient's medical and overall well-being, so the case for self-medication is even stronger.

I will now argue that the consequentialist and non-consequentialist reasons that I have presented in favour of DIC also justify a right of self-medication.

\section{MEDICAL OUTCOMES}

The first justification for the DIC posits that enabling patients to refuse treatment decisions leads to better medical outcomes in general, even if it enables poor decision-making in particular cases. This justification rests on an empirical hypothesis about the effects of informed consent. Setting aside the question of whether the data tell in favour of informed consent, what can this justification say about the prescription drug system? In this section I will present some evidence to suggest that a right of self-medication doesn't necessarily have worse public health consequences than a prescription drug system. In fact, the consequences might be better.

In the USA, the prescription drug system emerged in 1938 and was firmly in place by 1941. Sam Peltzman analysed time series data from the US vital statistics report from 1900 to 1980, and found that the introduction of a prescription drug system in the 1940s did not reduce mortality from accidental or suicidal poisonings. Instead, the introduction of a prescription-only category of drugs correlated with more fatal poisonings. ${ }^{18}$

One explanation for the seeming ineffectiveness of a prescription drug system is that prescription-only designation coincided with an explosion of new and dangerous drugs. Perhaps fatal poisonings would have increased were it not for a prescription-only system. Comparative data between countries suggests this is not the case. Peltzman compared middle-income countries with enforced prescription drug systems (Argentina, Uruguay, Ireland, Israel, Italy Portugal, Spain and Japan) with countries that did not enforce prescription drug laws (Chile, Colombia, Ecuador, Mexico, Peru, Venezuela, Greece, Yugoslavia, Egypt, Hong Kong, Philippines, Singapore and Thailand). Peltzman found that controlling for the effect of income and income inequality on infectious disease mortality, enforced prohibitions on prescription drugs did not reduce mortality from infectious diseases. ${ }^{18}$ If anything, middle-income countries that enforced prescription drug prohibitions sometimes had higher mortality rates, perhaps because prescriptions were unavailable to some patients who needed them.

In the same study, Peltzman found that poisoning mortality does not increase in non-prohibitive countries. In fact, states that enforced prescription-only drug regulations had $50-100 \%$ higher rates of poisoning mortality than non-prohibitive countries. In both the comparative and time-series analysis, Peltzman hypothesises that the paradoxical increase in drug misuse can be attributed to the fact that patients are more likely to consume potent and risky drugs when a physician endorses their choice, so prescription-only regimes actually encourage dangerous drug use by making the authorised use of dangerous drugs seem safe. Peter Temin's research has also found that the benefits of switching prescription-only drugs to over-the-counter status greatly outweigh the costs. ${ }^{19}$ Recent research also affirms that non-prescription availability can improve access to effective drugs, thus promoting better clinical outcomes and public health, and further involving consumers in their healthcare choices. ${ }^{20}$

These considerations indicate that prescription drugs systems do not promote patient health, but perhaps this study masks a more general cost of non-prohibitive regimes. Perhaps the option to access any medication would cause greater patient anxiety and dissatisfaction. Some philosophers have expressed this concern about physician-assisted suicide-if deadly drugs were available, a terminally ill patient might feel pressured to use them. ${ }^{15}$ Psychologists have established that more consumer choices do tend to cause anxiety and can leave consumers unhappy regardless of how they ultimately choose. ${ }^{21}$ On the other hand, experimental economists and psychologists have also shown that people display 'diversification bias', meaning that consumers tend to value having options in the future and will pay irrationally high prices to preserve even low-value future options. ${ }^{22}$ Both of these findings are relevant to the 'medical outcomes' justification for DIC and the right of selfmedication. These considerations show that the presence of more consumer choice, including pharmaceuticals, may cause anxiety and dissatisfaction, but patients might nevertheless value having more treatment options.

Even if an institutionalised right of self-medication did cause more anxiety for all patients, widespread low-level unease wouldn't necessarily outweigh the anxiety and frustration that is borne by patients who would take advantage of medical options that they presently lack under prohibitive regimes. Adopting a DIC may have enabled medically inadvisable refusal decisions and caused a great deal of anxiety for patients who learnt of diagnoses they wouldn't otherwise have known, but the macro-effects of DIC caused better medical outcomes on balance and many patients were spared unwanted medical interventions. Similarly, adopting a right of self-medication would enable patients to access medically inadvisable treatments and might cause patients to experience more anxiety about their medical choices, but on-balance prohibitive pharmaceutical policies make patients medically worse off. Further, prohibiting some treatment options is not necessary to mitigate the anxiety caused by more medical options. In a non-prohibitive prescription drug system, patients could autonomously decide to delegate judgements about best treatment options to doctors and avoid the pressure and anxiety associated with choosing from many different treatments, but those who disagreed with physicians' judgements would enjoy additional options.

This discussion of the medical costs of the prescription drug system has only been a sketch, but the evidence I have presented suggests that on balance, a right to self-medication would have better medical consequences than the status quo. Thus, just as the DIC was developed, in part, to make patients and society better off, so too should a right of self-medication.

\section{EPISTEMIC AUTHORITY}

Now consider the epistemic authority justification for DIC, which states that while physicians might be experts about a patient's medical well-being, patients are best suited to make decisions about their 'all-things-considered' well-being. The current restrictions on pharmaceuticals are designed to promote patients' health, but not their overall well-being. For this reason, a prescription drug system is incompatible with this justification for informed consent. 
To see how the prescription drug system privileges physicians' judgements about treatment over patients', consider the example of Adderall:

\begin{abstract}
Adderall: While Adderall is only prescribed for the treatment of attention deficit disorder, a growing number of students and workers without $\mathrm{ADD}$ have found that taking Adderall increases their performance and productivity. Yet people without a diagnosis of ADD cannot legally buy Adderall because they do not have a physician's prescription for the drug. Consequently, black markets for Adderall have formed at college campuses, but those who purchase the drug without a prescription do so illegally.
\end{abstract}

Just like patients with $\mathrm{ADD}$ who give informed consent to take Adderall, black market Adderall consumers judge that the potential benefits of taking Adderall outweigh the risks. Physicians and pharmaceutical regulators permit access to a drug if they judge that the medical benefits outweigh the medical risks When drugs don't provide any medical benefit, no amount of risk can justify their prescription, so patients without medical conditions lack access to potentially beneficial drugs. For example, we can imagine that the overall benefit of Adderall for some kinds of students and workers without $\mathrm{ADD}$ would be even greater than the overall benefit of Adderall for patients with ADD.

Compare, for example, a college student in a highly competitive and stressful environment, who must complete projects that require a great deal of focus, with an independently wealthy man of leisure who has $\mathrm{ADD}$, but no pressing deadlines or goals. While the wealthy man of leisure might have more of a medical reason to use Adderall, the benefits of the drug for his life as a whole don't exceed the benefits that the college student would enjoy.

The DIC is justified in part by the idea that the patient is in a better position than physicians to judge whether the overall benefits and risks of consenting to a treatment are justified given her life as a whole and to refuse if they are not. If a patient decides that consenting, though medically advisable, isn't advisable given her projects and commitments, the physician ought to defer to her judgement about the treatment decision. The prescription drug system deprives patients of that deference. Prescription-only prohibitions privilege physicians' and regulators' judgements about what is medically advisable over the patient's judgements about which treatment decision makes the most sense given her life as a whole.

These prohibitive policies are at odds with informed consent, and also with other areas of medicine like cosmetic surgery. Even though cosmetic surgery does not provide patients with any medical benefit and carries significant risks in many cases, physicians still provide patients with cosmetic procedures because their patients are willing to accept some level of medical risk for an overall, non-medical benefit. If patients can assume medical risks for overall benefits in this case, why not for prescription drugs as well? When a physician or regulator makes a decision about whether to designate a drug as prescriptiononly, that decision is based on the risk/benefit ratio of the drug, which then depends on the severity of the condition it treats. This means that gatekeepers accept more risk for conditions that are particularly painful or dangerous because the potential benefits are greater. Yet this judgement is a normative judgement, not a scientific judgement. Medical experts might be best placed to accurately determine the risks and benefits associated with a drug, but it doesn't follow that they are best placed to determine whether the medical risks are worth the potential overall benefits.
Still, the medical expertise of physicians is relevant to a patient's judgement about her overall interest. Many of us have a strong interest in preserving our health, and information about whether a treatment is medically advisable is an important public good. However, prohibitive policies are not necessary for the provision of the public good of medical advice. Pharmaceutical regulators and physicians might certify new drugs as safe, effective, or advisable without prohibiting patients from accessing unsafe drugs. The 'behind-the-counter' model might be extended to all drugs, meaning that in order to access a drug patients must consult a pharmacist or physician about the expected risks and benefits (or 'opt out' of these information requirements and perhaps waive the legal right to sue in case of adverse effects). In this way, patients could still access the judgement of medical experts, but where they judged that their overall well-being differed from an expert's judgement about their medical well-being, they could still access their chosen treatment.

\section{NORMATIVE AUTHORITY}

The third and strongest justification is based on the nonconsequentialist premise that physicians ought to respect patients' autonomous self-regarding choices about what they do with their own bodies. This justification maintains that physicians ought to respect patients' autonomous decisions, even if they are not in patients' medical or overall interests. As I described above, there are many reasons to accept that patient autonomy is a value that medical practice ought to respect. Here I will argue that the value of patient autonomy also tells in favour of self-medication.

Most clearly, this justification is the best interpretation of the doctrine of medical consent, as I argued above in the organ redistribution case. The value of patient autonomy is also the basis of informed consent: physicians cannot mislead or coerce patients into consenting to treatment. Even if a physician never forces a treatment on a patient, he can still violate her right to make decisions about her own body if he threatens her, or withholds relevant information, or lies. The right of informed consent has negative and positive elements. DIC establishes a negative right against coercion, deception and bodily interference, and a positive right to access necessary information to make an informed decision. Healthcare providers therefore have a duty to ensure that they present all relevant information and can be blamed for their negligence if they fail to do so, even if they do not deceive. Even if a provider blamelessly fails to provide information that is relevant to a treatment decision, a lack of information nevertheless undermines the patient's ability to autonomously choose, even though no one wronged the patient by coercing or deceiving her. ${ }^{23}$

Similarly, prescription drug regulations offend against the value of patient autonomy and are inconsistent with the 'normative authority' justification for DIC. Even when a patient autonomously chooses to make risky refusal-based decisions that will probably undermine or destroy her autonomous capacities in the long run, physicians and regulators must respect those decisions and are not entitled to prevent her from accessing treatments. Patient autonomy is not the kind of value that physicians should merely promote within some consequentialist calculus. Rather, the value of patient autonomy places deontic constraints on the conduct of medical professionals. Public officials, physicians, and pharmacists can only permissibly act to promote patients' autonomous capacities in ways that accord with due respect for the patients. Coercively interfering with a patient's treatment decisions, whether they 
are refusal-based or access-based, does not accord with due respect and is therefore impermissible even when interference would preserve the patient's autonomous capacities in the long run.

Like other negative rights including informed consent, selfmedication has positive elements in that it requires accommodation and non-interference. If a citizen has a negative right that people not interfere with her personal property and public officials fail to enforce her property claim, then public institutions fail to protect her property rights. This doesn't mean that officials need to provide citizens with personal property. Rather, this example shows that negative rights sometimes require the positive provision of some kind of accommodation. If DIC has such a positive element, public institutions must not only affirm, but enforce, DIC. If a patient seeks to use a prescriptiongrade treatment, her right to do so merits enforcement, meaning that pharmacists and physicians must be legally required to allow universal access to whatever treatments they provide.

DIC also protects patients' rights to access all relevant information about treatment options and in this sense the positive provision of some treatment-relevant goods is required for patients to make informed treatment decisions. Information isn't the only thing required to make a treatment decision-in some cases the treatment itself is required as well. That is, just as physicians are required to provide information to fully ensure that patients are making their own treatment decisions, physicians must also provide access. Yet this positive element of selfmedication only goes so far. While consumers are entitled to effective access, self-medication does not require that manufacturers or the government provide patients with pharmaceuticals - it only requires that they not stand in patients' way when they wish to have what is available to others and that they protect patients' rights to access pharmaceuticals.

\section{A NON-PROHIBITIVE PROPOSAL}

I have suggested that patients have rights of self-medication and that the prescription drug system violates this right. In practice, how exactly could a system be reformed to respect the right of self-medication? The natural answer is that prescription drug systems should become non-prohibitive, which means that patients should have protected legal access to medicines that are currently only available with a physician's notice.

In practice, this means that prescription-grade drugs should be sold either over the counter or behind the counter. In order to ensure that patients truly consent to dangerous drugs, governments or manufacturers might encourage patients to discuss the potential risks and benefits with a pharmacist or physician before purchasing the drug. Since informed consent requires that patients have access to any relevant information before making a treatment decision so too might the right of self-medication. Similarly, just as informed consent enables some patients to 'opt out' of knowing some relevant information, a prescription drug system ought to allow patients to opt out of behind-the-counter information requirements as well. Whether she satisfies the information requirement or 'opts out' of it, if a patient knowingly chooses to make a medically inadvisable treatment decision, I have argued that she has the right to do so and that that right warrants legal protection.

Some people have the intuition that manufacturers, regulators, or physicians should be held responsible for harms caused to patients by dangerous drugs. This intuition is understandable given the prescription drug system that is in place today, since manufacturers, regulators and physicians all play a role in shaping patients' decisions about which treatments to use. By proposing that patients have protected rights to self-medication, I also am arguing that patients ought to be permitted to make treatment decisions without involving regulatory agencies or physicians.

If patients could take responsibility for health choices and make treatment decisions in light of all relevant information about the risks and benefits of a drug, then by consenting to the drug, patients could waive their rights against risk and harm and absolve regulators, manufacturers and physicians of responsibility for any adverse effects. As a consequence, third parties would not necessarily be complicit in dangerous treatment decisions, as they are today either when they withhold or grant access to dangerous medicines. This is similar to Richard Epstein's proposal for malpractice reform. Epstein suggests that consenting patients ought to be able to accept certain risks in advance of treatment and waive their rights to sue physicians. ${ }^{24}$

A non-prohibitive pharmaceutical system would also avoid the enforcement costs associated with prohibitive prescription drug systems. Pharmaceuticals have become part of the war on drugs and users and distributors of illegal pharmaceuticals face criminal penalties, including imprisonment. Decriminalising the use of prescription medications would eliminate the financial and human cost of criminal investigation and punishment for prescription drug users.

Still, there is a role for government enforcement and prohibitions. Manufacturers ought to be criminally prohibited from selling adulterated and contaminated drugs, from failing to disclose all relevant information about the known risks and benefits of drugs and from making fraudulent claims in advertisements or labels. In cases of fraud or gross negligence patients do not waive their rights against risk because they were misinformed and did not give genuine consent to a drug. ${ }^{25}$ For this reason, manufacturers whose misbranded or contaminated products harm patients are criminally liable for medical battery in the same way as grossly negligent and deceitful physicians.

My suggestion that pharmaceutical regulation should be nonprohibitive does not mean that patients are required to assume full responsibility for treatment decisions. Just as citizens can cede some responsibility for their tax filings to an accountant, patients can partially share responsibility for their health choices with a physician if they designate a physician to act as their agent. It does mean though that patients are responsible for treatment decisions to some extent in that they must at least make the decision to designate a physician to act as an agent on their behalf

\section{DANGEROUS DRUGS}

One objection to the proposal I have outlined is that patients cannot permissibly expose themselves to the risks posed by dangerous drugs, either because self-harming is wrong or because it is costly to the public. Earlier, I argued against the idea that medical professionals should promote patients' autonomous capacities by prohibiting dangerous choices, but even if a patient is owed respect it might still be wrong for her to undermine her own autonomous capacities. This is like David Velleman's suggestion that patients do not have the right to die because they cannot waive the right to life. ${ }^{15}$ For a similar reason, Samuel Freeman and Peter De Marneffe have argued against recreational drug use on the grounds that users are not entitled to undermine or damage their autonomous capacities. ${ }^{26} 27$ Taking this tack, one might argue that it is wrong for patients to undermine their autonomous capacities with dangerous pharmaceuticals. Yet even if patients don't have the right to undermine their autonomous capacities, they nevertheless have extensive rights of self-medication for three reasons. 
First, we should note that most pharmaceuticals do not carry deadly risks when used properly and that many non-prescription grade drugs are very risky when misused. Acetaminophen alone is responsible for over 400 deaths every year in the USA, so the match between prescription-grade drugs and risk is imperfect. This objection therefore does not tell against unrestricted access to many prescription-grade drugs which would not undermine or damage patients' autonomous capacities. When a patient receives a prescription for a drug, the drug does not become less dangerous. Since patients with prescriptions do not act wrongly when they use dangerous drugs that risk undermining their capacities, taking dangerous drugs is not in itself wrong whether a patient has a prescription or not.

Perhaps prescription requirements aim to parse out whether a drug will be dangerous for a particular patient who may suffer from a drug interaction or allergies, but this line of response does not justify prohibitive policies either because prescription drug requirements apply universally to all patients without an authorised medical condition, even those without particular risk factors like allergies or interactions. Similarly, just as patients who consent to use drugs prescribed by physicians accept the risks associated with the treatment, if a patient could permissibly accept the risk of a drug if she had a medical condition, the absence of a medical condition shouldn't bear on the permissibility of exposing herself to the risks of a drug.

Second, while the proposal I have outlined would enable patients to mix drugs in inadvisable ways, perhaps for recreational use, or to take deadly quantities of secobarbital sodium or pentobarbital, This objection isn't a consideration against self-medication because even if it is impermissible for patients to undertake extremely risky, undermining, or deadly treatment they might still have rights to access medicines that could be extremely risky or deadly or undermining. Consider some analogous cases. We might think that people don't have the right to use firearms in a dangerous or selfharming way, but that they nevertheless have the right to use firearms that could be dangerous or self-harming. Even if people don't have the right to risk their lives or kill themselves by jumping off buildings, they still might have the right to stand on rooftops

Third, the worry that the public will bear the cost of unrestricted pharmaceutical access is empirically misplaced and normatively suspect, but it does illustrate one limit of selfmedication. Empirically, Peltzman's analysis above also found that in non-prohibitive regimes patients are more cautious when accessing highly potent pharmaceuticals and less prone to misuse and that public health outcomes might even be better (all else held equal) without enforced prohibitions. Further, patients in a non-prohibitive regime could still choose to consult physicians and pharmacists as before, thus mitigating the risk of misuse. In any case, since self-medication is a right then the public might rightly be asked to bear the costs of accommodation just as public institutions accommodate the negative externalities of other exercises of basic rights.

Still, the right of self-medication is not absolute. If selfmedication choices like antibiotic use would cause public health disasters like antibiotic-resistant contagious 'superbugs' then the right of self-medication can rightly be limited to mitigate the harm of contagious illness. This caveat doesn't undermine the deontic force of a right of self-medication though, as even informed consent and informed refusal are sometimes permissibly outweighed by public health risks-for example, when contagious illnesses prompt quarantine and mandatory vaccination policies.

\section{ADDICTION AND ABUSE}

A related worry is that a non-prohibitive prescription system will lead to widespread drug abuse and addiction. The sale of black market painkillers has received increasing media attention and pharmaceutical addiction has ruined patients' lives in the same way as addictive recreational drugs.

Yet, as with recreational drugs, evidence does not support the hypothesis that patients are better off all-things-considered as a result of prohibitive policies. Just as many policy experts and ethicists like Douglas Husak favour decriminalisation of recreational drugs because the cost of drug wars is unacceptably high given the effects of drug use, so too should they favour the decriminalisation of prescription drugs. ${ }^{28}$ Yet the case for decriminalisation of pharmaceuticals is even stronger than that for recreational drugs because many illegal users of pharmaceuticals use the drugs for legitimate medical purposes, not because they are addicts using the drugs recreationally. For example, in the United States it is common for elderly patients who cannot afford US prescription drug prices to illegally purchase cholesterol and blood pressure medication from Canadian pharmacies. These patients are also subject to criminal sanction for illegal pharmaceutical use, although they are treating a medical condition.

Still, some prescription drugs are addictive and addicts might be better off without unrestricted access to them. However, recent philosophical and empirical investigations into addiction by Bennett Foddy and Julian Savulescu have persuasively shown that drug addiction does not undermine an addict's capacity to act autonomously or to consent to his drug of choice because most addicts will refuse their drugs of choice given strong enough incentives. ${ }^{29}$ Since addicts are autonomous and able to give informed consent for treatment, including for their drug of choice, they ought to be granted similar authority to access treatment, including their drug of choice. One way to mitigate the potential harm of addictive pharmaceuticals would be to designate some addictive drugs as 'behind the counter' and enable addicts who do not wish to use addictive pharmaceuticals to precommit to not using by enrolling in a voluntary prohibition programme. Casinos have used this strategy to help gambling addicts without withholding entry to casinos from customers who endorse their desire to gamble.

\section{CONCLUSION}

I have argued that the prescription drug system is unjust because it violates citizens' rights of self-medication. Citizens have rights of self-medication for the same reasons that they have rights of informed consent. The prescription drug system has bad consequences and it privileges regulators' and physicians' judgements about a patient's health over the patient's judgement about her overall well-being. Most troublingly, the prescription drug system violates patients' rights.

Instead, I propose that prohibitive pharmaceutical policies, which are a kind of strong paternalism, be replaced by nonprohibitive policies that enable patients to obtain whatever medicines they choose while promoting informed consumer choices by making expert advice readily available.

This argument has implications beyond the prescription drug system. A right of self-medication might also be invoked to justify a right to die, recreational drug use, or the abolition of prohibitive premarket testing for experimental medicines, though I have not argued for any of these policies here. This argument for self-medication also requires that physicians as well as regulators rethink their role in patients' lives. Patients ought to be regarded as the ultimate authority when it comes to decisions about their own bodies. But patients' authority doesn't 
stop at their ability to refuse treatment. In order to truly respect patients' rights, states must also abolish prescription drug requirements and recognise rights to self-medication.

Acknowledgements $A$ version of this paper was presented at the Princeton University political theory research seminar, and at the Princeton Human Values Forum. I also presented this essay at the University of Richmond, Kansas State University, Bowling Green State University and Brown University. I am very grateful for the comments from the audiences there, as well as from Javier Hidalgo, Ryan Davis, Peter Singer, Stephen Macedo, Christian Coons and Anna Stilz.

Contributors Jessica Flanigan wrote this essay.

Competing interests None.

Provenance and peer review Commissioned; externally peer reviewed.

\section{REFERENCES}

1. Miller FG, Wertheimer A. Facing up to paternalism in research ethics. Hastings Cent Rep 2007;37:24-34.

2. Carpenter D. Reputation and Power. Princeton, NJ: Princeton University Press, 2010.

3. Dolgin JL. The legal development of the informed consent doctrine: past and present. Camb 0 Healthc Ethics 2010;19:97.

4. Salgo v. Leland Stanford Jr. University Board of Trustees, 154 Cal.App.2d 560. Judicial opinion, 1957.

5. Young R. Informed consent and patient autonomy. In: Kuhse $H$, Singer $\mathrm{P}$, eds. $A$ Companion to Bioethics. Blackwell, 2010:441-51.

6. Gillon R. Ethics needs principles-four can encompass the rest-and respect for autonomy should be "first among equals". J Med Ethics 2003;29:307-31.

7. Laine C. Davidoff F. Patient-Centered medicine: a professional Evolution. JAMA 1996;275:152-6.

8. Mill JS. On Liberty. Oxford University Press, 2008:83-104.

9. Veatch RM. Abandoning informed consent. Hastings Cent Rep 1995;25:5-12.
10. Beauchamp TL, Childress J. Principles in Biomedical Ethics. 5th edn. Oxford New York: Oxford University Press, 2001:398.

11. Korsgaard C. The Sources of Normativity. New York, NY: Cambridge University Press. 1996.

12. Darwall S. The Second Person Standpoint. Cambridge, MA: Harvard University Press, 2009.

13. Scanlon TM. What We Owe to Each Other. Cambridge, MA: Harvard University Press, 1999.

14. Beauchamp TL. Methods and principles in biomedical ethics. J Med Ethics 2003;29:269-74

15. Velleman JD. Against the right to die. J Med Philos 1992;17:665-81.

16. Laurie GT. In defense of ignorance: genetic information and the right not to know. Eur J Health Law 1999;6:119-32.

17. Davis JK. Precedent autonomy and subsequent consent. Ethical Theory Moral Pract 2004:7:267-91.

18. Peltzman S. The health effects of mandatory prescriptions. J Law Econ 1987;30:207

19. Temin P. Realized benefits from switching drugs. J Law Econ 1992;35:351-69.

20. Brass EP, Lofstedt R, Renn 0. Improving the decision-making process for nonprescription drugs: a framework for benefit-risk assessment. Clin Pharmacol Ther 2011:90:791-803.

21. Schwartz B. The Paradox of Choice. New York, NY: Harper Perennial, 2005.

22. Read D, Loewenstein G. Diversification bias: Explaining the discrepancy in variety seeking between combined and separated choices. J Exp Psychol App/ 1995:1:34-49.

23. Taylor JS. Practical Autonomy and Bioethics. Routledge, 2009:131.

24. Epstein R. Contractual principle versus legislative fixes: coming to closure on the unending travails of medical malpractice. DePaul Law Review 2005;54:503.

25. Korsgaard C. Two Arguments against Lying in Creating the Kingdom of Ends. Cambridge University Press, 1996:335-62.

26. Freeman S. Liberalism, inalienability, and rights of drug use. In: De Greiff $P$, ed. Drugs and the Limits of Liberalism. Cornell University Press, 1999:110-30.

27. De Marneffe P. Do we have a right to use drugs? Publ Aff 0 1996:10:229-47.

28. Husak DN. Recreational drugs and paternalism. Law Philos 1989;8:353-81.

29. Foddy B, Savulescu J. Addiction and autonomy: can addicted people consent to the prescription of their drug of addiction? Bioethics 2006:20:1-15. 